\title{
The Pierre Limoges Pediatric Anesthesia Lecture: Tricky problems in pediatric anesthesia
}

Josée Lavoie MD FRCPC

$\mathrm{T}$ HE Pediatric Refresher Course Lecture was re-named in 2003 and has become the Pierre Limoges Pediatric Anesthesia Lecture. Pierre Limoges was a formidable pediatric anesthesiologist. He was a superb clinician, attentive teacher and respected colleague. This lecture is meant to resemble Pierre Limoges and be clinically relevant to anesthesiologists working in the community and in tertiary care centres alike. Three scenarios shall be explored because of pertinent first line management issues as well as tertiary care interest. The first scenario is idiopathic hypertrophic pyloric stenosis (IHPS), a common condition affecting young infants. Recent developments in anesthetic technique and postoperative considerations shall be reviewed. The second case scenario is the patient with lingual tonsil hypertrophy (LTH). Although rare, anesthesiologists should be alerted to this condition which may be associated with a difficult airway. Clinical presentation, risk factors and major airway management issues will be discussed. Finally, the third tricky situation is the child with aspiration of a foreign body (FB). Full management issues will be discussed with emphasis on anesthesia technique and postoperative monitoring.

\section{The infant with IHPS}

IHPS typically occurs at four to six weeks of life and is characterized by emesis, which is described as projectile. The infant feeds well and is obviously hungry but develops projectile vomiting shortly after feeding. The incidence varies between two to five per 1,000 live births per year but it may be declining. ${ }^{l}$ It is more common in Caucasian populations and in male infants, the male to female ratio being approximately $4: 1$. Although there is a familial link, the transmission is likely polygenic. The etiology has not been clearly elucidated and environmental factors, such as early infant or maternal exposure to erythromycin and maternal smoking, have also been implicated. ${ }^{2}$ A recent report by Persson, describes parallel incidences of sudden infant death syndrome (SIDS) and IHPS. ${ }^{3}$ Both the incidences of SIDS and
IHPS dropped in the early 1990's, in Sweden, coinciding with the "back to sleep" campaign. Persson suggests that prone sleeping may be a common causative factor of SIDS and IHPS.

Because vomiting leads to depletion of sodium, potassium and hydrochloric acid, metabolic alkalosis, hypochloremia and hypokalemia thus characterize laboratory findings. However, in a recent publication, Schwartz found that $36 \%$ of 143 infants with IHPS presented hyperkalemia and only $10 \%$ were hypokalemic. ${ }^{4}$ The kidney, to conserve sodium and maintain intravascular volume, excretes hydrogen ions, further aggravating the metabolic alkalosis. Hypovolemia and hyponatremia may also be present but these findings are less frequent in the current era of early diagnosis. Indirect hyperbilirubinemia may occur in less than $2 \%$ of patients and is caused by decreased hepatic glucuronyl transferase activity.

The diagnosis can be made either clinically, by abdominal ultrasound or, rarely, by upper gastrointestinal examination ("barium meal"). In the majority of cases, abdominal ultrasound is the confirmatory diagnostic tool. The increased reliance on this rapid and accurate imaging technique may have contributed to fading clinical skills. ${ }^{5}$

IHPS is a medical emergency and hypovolemia and metabolic abnormalities should be corrected prior to surgery. Once the alkalosis, electrolytic and hydration anomalies have been corrected, surgery should proceed expeditiously. Intraoperatively, pre-induction blind aspiration of gastric content is recommended but one should be alert to the possibility of residual gastric fluid. Atropine is given prior to aspiration and removal of the gastric tube to avoid vagal reactions. Cook-Sather quantified the average volume of gastric fluid removed by blind aspiration in infants scheduled for pyloromyotomy. ${ }^{6}$ The average volume was $4.8 \pm$ $4.3 \mathrm{~mL} \cdot \mathrm{kg}^{-1}$ with $83 \%$ of patients having volumes above $1.25 \mathrm{~mL} \cdot \mathrm{kg}^{-1}$. Blind aspiration of gastric fluid was effective in retrieving $96 \%$ of the fluid.

From the Department of Anesthesia, Montreal Children's Hospital, McGill University Health Center, Montreal, Quebec, Canada.

Address correspondence to: Dr. Josée Lavoie, Department of Anesthesia, Montreal Children's Hospital, McGill University Health Center, 2300 Tupper Street, Montreal, Quebec H3H 1P3, Canada. E-mail: josee.lavoie@muhc.mcgill.ca 
Many anesthetic techniques have been used for pyloromyotomy. In 1951, Browne advocated the use of local anesthesia, a technique that has since been abandoned. ${ }^{7}$ There are reports of caudal, as well as spinal anesthesia, being used for this procedure. ${ }^{8-10}$ Spinal anesthesia has been reported as effective and safe in this patient population. Somri describes the successful use of spinal anesthesia in 23 of 25 infants scheduled for pyloromyotomy, using hyperbaric bupivacaine $0.5 \%$, $0.8 \mathrm{mg} \cdot \mathrm{kg}^{-1} \cdot{ }^{10}$ The sensory levels achieved ranged between $\mathrm{T} 3$ and $\mathrm{T} 5$. Hemodynamic variables remained stable during the procedure when compared to the prespinal levels. None of the patients presented apneic events during or after surgery. Postoperatively, only five patients required acetaminophen for pain control and none required opioids.

General endotracheal anesthesia with rapid sequence induction, is the most frequently used anesthetic technique for pyloromyotomy. Awake intubations are seldom performed currently. Cooke-Sather prospectively studied 76 infants undergoing pyloromyotomy and compared awake $v s$ paralyzed tracheal intubation. ${ }^{11}$ The author found that the infants were more likely to require multiple and more prolonged attempts at intubation with an awake technique. However, the number of desaturation episodes and bradycardias was not different between both groups. Thiopental and propofol have been used for induction whereas succinylcholine is the most commonly used muscle relaxant for rapid sequence induction in this patient population. Halogenated anesthetic agents have been predominantly used for maintenance of anesthesia but the use of propofol and remifentanil have also been reported. Desflurane has been compared to isoflurane during pyloromyotomy with respect to recovery characteristics and postoperative apnea. ${ }^{12}$ Time to extubation was shorter in the desflurane group and postoperative apnea occurred in three of 11 isoflurane patients compared to none in the desflurane group. More recently, remifentanil has been compared to halothane in patients undergoing pyloromyotomy. ${ }^{13}$ Recovery profiles were similar, however, three patients in the halothane group presented abnormal postoperative pneumograms (although their preoperative pneumogram was normal) compared to none in the remifentanil group. Intraoperatively, care should be taken to provide adequate depth of anesthesia for a quiet surgical field to avoid complications of the Ramstedt pyloromyotomy such as mucosal tear and bleeding.

Recently, the use of laparoscopic technique has been advocated. Conclusions on the use of this technique are contrasting, this approach has been associat- ed with a higher complication rate and has not been deemed cost-effective by some, whereas others have found similar efficiency but less wound complications and less postoperative emesis. ${ }^{14,15}$

The incidence of postoperative apnea has not been well documented in this patient population. However, Chipps does provide some insight into the matter. ${ }^{16}$ His group prospectively studied 30 infants with pyloric stenosis, who underwent pre and postoperative sleep studies. The goal of the study was to determine their postoperative apnea risk. The infants underwent pyloromyotomy under opioid-free, general anesthesia. Postoperative analgesia was provided by $i v$ ketorolac, rectal acetaminophen and wound infiltration. The sleep studies were remarkable for increased apnea indices preoperatively. Postoperatively, the apnea indices were significantly decreased in all infants. The authors conclude that, the general anesthesia technique provided for pyloromyotomy, in their study, did not induce postoperative apnea. In contradiction with Chipps, Andropoulos reports on postanesthetic apnea in four full-term infants after pyloromyotomy. ${ }^{17}$ None of the infants had received narcotics. One of the hypothesis brought forth to explain the occurrence of apnea postoperatively, is that cerebrospinal $\mathrm{pH}$ may still be elevated despite normalization of blood $\mathrm{pH}$. Cerebrospinal fluid (CSF) $\mathrm{pH}$, being one of the determinants of respiratory drive, this CSF alkalosis may lead to postoperative apnea. Other potential causes of apnea may be the presence of residual anesthetics, aspiration of feedings and/or partial airway obstruction caused by secretions. Thus, it would be wise to exert caution and perform apnea monitoring for $24 \mathrm{hr}$ post-pyloromyotomy.

An audit of postoperative analgesia for pyloromyotomy is reported by Habre et al. ${ }^{18}$ The authors report on 72 post-pyloromyotomy patients. There was a low consumption of analgesics with only three patients requiring opioids postoperatively and, on average, two doses of acetaminophen. Twenty-five percent of infants did receive opioids at induction of anesthesia. Postoperative analgesia was provided with local wound infiltration and rectal acetaminophen.

The postoperative feeding regimen has changed and now allows ad libitum feeding. This practice has been described as safe, cost-effective and has decreased hospital stay without increasing the incidence of postoperative vomitting. ${ }^{19}$

There is considerable debate over who should be caring for infants with IHPS: should these infants be managed in specialized centres or in the community? White performed a retrospective analysis of 160 infants treated in a district general hospital of 
Belfast. ${ }^{20}$ Mortality was 0 and morbidity was comparable to that reported by specialized pediatric units. The author concluded that these infants could be safely treated in the community provided there are appropriately trained surgical, anesthetic and pediatric staff. Dubé and colleagues, ${ }^{21}$ in addition to Saunders' group, ${ }^{22}$ came to similar conclusions. However, Pranikoff's group has come to a different conclusion. ${ }^{23}$ The authors retrospectively reviewed 780 cases of pyloromyotomy in North Carolina hospitals. They found a greater rate of mucosal perforation and higher hospital costs when general surgeons provided care for patients with IHPS compared to pediatric surgeons. A current medical trend is to determine the quantity of patients that constitutes an adequate caseload to provide sufficient exposure to maintain professional skills. Several studies have shown that all pediatric age groups are at higher risk of complications during anesthesia. ${ }^{24,25}$ Cardiac arrest occurs much more frequently in the neonate and the infant than the older child. Specialty care for the pediatric age groups has been advocated by Keenan who examined a database of over 100,000 anesthetics. ${ }^{26}$ All of the pediatric cardiac arrests occurred in children aged less than one year, whose anesthetic was supervised by an anesthesiologist who did not care for children on a regular basis. Should children with IHPS be cared for exclusively in tertiary care centres? The answer is equivocal. However, care of these infants should most certainly be concentrated in a limited number of centres, which may be community-based, and provided by appropriately trained and experienced personnel.

\section{LTH}

"The tissue at the base of the tongue is a most fertile source of trouble." 27

The lingual tonsil is a normal component of Waldeyer's ring along with the palatine and pharyngeal tonsils. It is not encapsulated and is limited anteriorly by the circumvallate papilla at the base of the tongue and, posteriorly, by the epiglottis. LTH has been blamed for unanticipated difficult airway situations. Reports range from cases of difficult ventilation to a fatal case of cerebral anoxia secondary to an inability to ventilate nor intubate a previously healthy and asymptomatic, 24-yr-old patient. ${ }^{28}$

Two patients were recently admitted to our institution with LTH. Both patients presented with respiratory distress and their airway management was critical, requiring close team work between anesthesiologist, otorhinolaryngologist and intensivist. One of these patients was a ten-year-old boy who presented with symptoms suggestive of obstructive sleep apnea. He was admitted after a sleep study revealed frequent oxygen desaturations with a nadir of $71 \%$. The subsequent investigation revealed benign lymphoid hyperplasia of the nasopharynx, oropharynx and supraglottic area. The patient underwent debulking of the lesion and pathology reports concluded on tonsillitis. At induction of anesthesia, ventilation was easy during spontaneous ventilation but there was increased airway resistance during positive pressure ventilation. Intubation was difficult as the vocal cords were briefly but barely visualized. The patient again presented obstructive sleep apnea secondary to LTH two months later, requiring another lingual tonsillectomy. The lingual tonsil mass obstructed the glottic view but intubation was somewhat easier than on the initial presentation. The patient remained intubated for nine days postoperatively due to significant airway edema.

In the pediatric literature, five cases of airway obstruction secondary to LTH have been reported. Guarisco reports on two patients. ${ }^{29}$ One is a nine-yearold boy with Down's syndrome who presented to the emergency department with acute stridor. LTH was diagnosed by rigid bronchoscopy performed under general anesthesia. It was noted that tonsillar tissue was extending into the valleculae and displacing the epiglottis posteriorly, causing subtotal obstruction of the glottis. Their second patient was a five-year-old boy, also referred for evaluation of obstructive sleep apnea. LTH was noted on awake, flexible fibreoptic endoscopy. During the induction of anesthesia for lingual tonsillectomy, there was significant difficulty with mask ventilation and nasotracheal intubation, as the enlarged tonsils obstructed the view of the epiglottis and the glottic opening. Conacher also describes a patient with Down's syndrome who presented with progressive obstructive sleep apnea caused by hypertrophied lingual tonsils. ${ }^{30}$ The patient presented no further symptoms of obstruction three months later. Nakazawa also submits a patient with Down's syndrome and obstructive sleep apnea due to LTH. ${ }^{31} \mathrm{~A}$ difficult airway was anticipated as the patient presented with a Mallampati 3 examination. Furthermore, a preoperative flexible laryngoscopy demonstrated hypertrophied lingual tonsils, an edematous epiglottis and the glottis could not be identified. Anesthesia was induced and ventilation was possible as long as the patient was breathing spontaneously, but difficult otherwise. Direct laryngoscopy failed but fibreoptic bronchoscopy, although difficult, was used successfully to intubate the patient. The patient remained intubated for six days postoperatively due to supraglottic edema. Tokumine describes a patient with symptomatic LTH causing, amongst other symptoms, obstructive sleep apnea. ${ }^{32}$ The author describes a diffi- 
cult technique of fibreoptic bronchoscopy under propofol sedation and spontaneous breathing. The procedure was complicated with bleeding from the surface of the lingual tonsils. The tonsillectomy was further complicated with postoperative bleeding, requiring an urgent surgical re-exploration for hemostasis. The patient remained intubated for two days postoperatively due to glottic edema.

Although the condition occurs less often in children than adults, pediatric patients may present with LTH. All of the pediatric patients reported above, as well as our two patients, were symptomatic for obstructive sleep apnea, unlike adult patients with LTH, who have been predominantly described as asymptomatic. Lingual tonsillectomy is a difficult technique fraught with potential bleeding complications and airway edema. The etiology of LTH has not been elucidated, albeit it may be a compensatory hypertrophy post-adenotonsillectomy. LTH has been associated with reflux disease. In fact, LTH has been reported in $75 \%$ of patients with symptoms of gastroesophageal reflux. ${ }^{33}$ Parham reports on a pediatric patient with recurrent $\mathrm{LTH}$, who was successfully treated with histamine ${ }_{2}$-receptor blockers with no recurrence of LTH after one year. ${ }^{34}$ Thus, risk factors for LTH, in pediatric patients, seem to include Down's syndrome, prior tonsillectomy and/or adenoidectomy and gastroesophageal reflux.

Anesthesiologists should be prepared for difficult airway management in pediatric patients with obstructive sleep apnea, which may be caused by LTH. Both ventilation and intubation can be difficult. The tonsillar tissue is friable and may bleed easily, further complicating airway management. Fibreoptic bronchoscopy may not be feasible due to the presence of blood in the airway and is not indicated in "cannot ventilate/cannot intubate" situations. Although the laryngeal mask airway has been used in LTH patients with difficult airways, it is not always successful. ${ }^{35}$ This supraglottic ventilatory tool may be of limited efficacy for patients with severe periglottic obstruction. One may be left with limited options such as needle cricothyroidotomy while awaiting a more definitive airway.

\section{Airway FB}

FB aspiration is amongst the leading causes of accidental deaths in the infant and accounts for $7 \%$ of deaths in children aged less than four years. The incidence is highest at age two. ${ }^{36}$ Food products are most commonly found in younger children, mostly peanuts but also hotdog sausages, popcorn, grapes and seeds. Inorganic FBs, found in the older child, include body piercing items, pins, needles, pen caps, paper clips and other school supplies. Pieces of latex balloons are responsible for the greatest number of fatal FB aspirations. ${ }^{37}$ Unfortunately, a clear history of choking is not always reported. Only $36 \%$ of patients present a history of choking prior to consultation. ${ }^{38}$ This often contributes to delayed diagnosis. In addition, an asymptomatic period may follow a choking episode and contribute to the delayed diagnosis, which may be longer than one week in 12 to $26 \%$ of patients. ${ }^{38}$ This delay may lead to additional morbidity caused by refractory pneumonia, bronchial hyperresponsiveness, bronchial inflammation and obstruction, bronchiectasis and bronchial synechia. ${ }^{39,40}$ Ninety-five percent of patients with FB aspiration will present with symptoms of coughing, wheezing and choking. ${ }^{38}$ Roentgenograms however, may be normal in up to $12 \%$ of patients. ${ }^{38}$ In children, $74 \%$ of airway FBs are found in the proximal airways: larynx, trachea, right and left mainstem bronchi. The incidence is not increased in the right compared to the left mainstem bronchi. ${ }^{38}$

Most FBs may be removed within $24 \mathrm{hr}$ of aspiration. However, expandable FBs such as peas, beans and popcorn should be removed as soon as possible, before they swell and cause complete airway obstruction. Although flexible bronchoscopic management of FBs has been advocated in children, rigid bronchoscopy remains the most widely used and accepted technique to remove $\mathrm{FB} .{ }^{41} \mathrm{~A}$ complete examination of the tracheobronchial tree is mandatory as there may be an additional FB or fragments of the original FB, lodged elsewhere. Anesthetic techniques may vary but it is recommended to maintain spontaneous breathing as positive pressure ventilation may dislodge the $\mathrm{FB}$ and cause complete airway obstruction. It is useful to spray the valleculae, epiglottis and vocal cords with lidocaine, using a syringe connected to an iv cannula. Rigid bronchoscopy is a highly stimulating procedure and depth of anesthesia should be adequately gauged to avoid unnecessary coughing or laryngospasm during the procedure. Coughing may dislodge the FB and cause total obstruction. The author's preferred technique is total $i v$ anesthesia, which has the advantage of avoiding environmental pollution. A combination of propofol and remifentanil infusions provides adequate depth of anesthesia, spontaneous ventilation and rapid awakening. The propofol infusion is initiated at 300 $\mu \mathrm{g} \cdot \mathrm{kg}^{-1} \cdot \mathrm{min}^{-1}$ and is rapidly decreased to 150 $\mu \mathrm{g} \cdot \mathrm{kg}^{-1} \cdot \mathrm{min}^{-1}$ whereas remifentanil is initiated at 0.2 $\mu \mathrm{g} \cdot \mathrm{kg}^{-1} \cdot \mathrm{min}^{-1}$ and may be decreased to 0.1 $\mu \mathrm{g} \cdot \mathrm{kg}^{-1} \cdot \mathrm{min}^{-1}$. Nitrous oxide is best avoided as it may aggravate the hyperinflation distal to the obstruction. Oxygenation and ventilation are performed through the ventilating arm of the rigid bronchoscope. A laryn- 
geal mask airway may be used for flexible bronchoscopic FB removal. ${ }^{42}$ During endoscopy, the FB may become dislodged and cause complete obstruction of the airway or it may lodge in the contralateral bronchial tree and obstruct the "good lung". In both situations, the patient's status may deteriorate rapidly. The FB should be grasped and removed immediately or put back to the original side. At this point, it may be necessary to administer a muscle relaxant to facilitate extraction of the FB. Ventilating pressures should be kept low to avoid lung hyperinflation. Helium in combination with oxygen may be used. ${ }^{43}$ Its lower density and higher viscosity contribute to decreased turbulence, better diffusion and increased volume of gas that can pass a given point per second. The patient may also be turned to the lateral position to favour movement of the FB. If the patient's condition continues to deteriorate, an urgent thoracotomy and bronchotomy/tracheotomy may be performed to remove the FB. ${ }^{44}$ Cardiopulmonary bypass and extracorporeal membrane oxygenation have also been used in extremis. ${ }^{45}$

Postoperatively, these children should be observed closely. They are at risk of respiratory obstruction caused by airway edema secondary to endoscopic manipulation. Dexamethasone $0.4 \mathrm{mg} \cdot \mathrm{kg}^{-1}$ may be indicated during a difficult and lengthy procedure, or if airway edema is suspected. Pneumothorax and pneumomediastinum may also complicate the postoperative course. In addition, negative pressure pulmonary edema may occur immediately after removal of the FB. ${ }^{46}$ Treatment includes supplemental oxygen and diuretics. Mechanical ventilation with positive end-expiratory pressure therapy may be required in up to $50 \%$ of patients.

In conclusion, many situations involving pediatric patients may be problematic. However, a thorough understanding of the pathophysiology combined with adequate preparation and planning will contribute to a favourable outcome. Outcome in pediatric anesthesiology has greatly improved in the past decade. This is due to the availability of specialized, age-specific equipment, better monitoring practices, improved training and awareness of the singularity of the pediatric patient.

\section{References}

I Hedbäck G, Abrahamsson K, Husberg B, Granbolm T, Odén $A$. The epidemiology of infantile hypertrophic stenosis in Sweden 1987-96. Arch Dis Child 2001; 85: 379-81.

2 Cooper WO, Griffin MR, Arbogast P, et al. Very early exposure to erythromycin and infantile hypertrophic pyloric stenosis. Arch Pediatr Adolesc Med 2002; 156:
647-50.

3 Persson S, Ekborn A, Granath F, Nordenskjöl A. Parallel incidences of sudden infant death syndrome and infantile hypertrophic pyloric stenosis: a common cause? Pediatrics 2001; 108: E70.

4 Schwartz D, Connelly NR, Manikantan P, Nicholds JH. Hyperkalemia and pyloric stenosis. Anesth Analg 2003; 97: 355-7.

5 Chen EA, Luks FI, Gilchrist BF, Wesselhoeft CW, DeLuca $F G$. Pyloric stenosis in the age of ultrasonography: fading skills, better patients? J Pediatr Surg 1996; 31: 829-30.

6 Cook-Sather SD, Tulloch HV, Liacouras CA, Schreiner $M S$. Gastric fluid volume in infants for pyloromyotomy. Can J Anaesth 1997; 44: 278-83.

7 Browne D. The Treatment of congenital hypertrophic pyloric stenosis. Proc R Soc Med 1951; 44: 1053-63.

8 Moya-Gardia D, Garza-Leyva M, Velazquez-Armenta EY, Nava-Ocampo AA. Caudal block with $4 \mathrm{mg} \mathrm{kg-1}$ ( $1.6 \mathrm{ml} \mathrm{kg}-1$ ) of bupivacaine $0.25 \%$ in children undergoing surgical correction of congenital pyloric stenosis. Paed Anaesth 2002; 12: 404-10.

9 Aguirreurreta NB, Cia Armendariz ML, Carrascona Moreno $S$, et al. Anestesia epidural caudal en la piloromiotomia del lactante: nuestra experiencia. Cir Pediatr 2000; 12: 153-5.

10 Somri M, Gaitini LA, Vaida SJ, et al. The effectiveness and safety of spinal anaesthesia in the pyloromyotomy procedure. Paed Anaesth 2003; 13: 32-7.

11 Cooke-Sather SD, Tulloch HV, Cnaan A, et al. A comparison of awake versus paralysed tracheal intubation for infants with pyloric stenosis. Anesth Analg 1998; 86: 945-51.

12 Wolf AR, Lawson RA, Dryden CM, Davies FW. Recovery after desflurane anesthesia in the infant : comparison with isoflurane. Br J Anaesth 1996; 76 : 362-4.

13 Davis PJ, Galinkin J, McGowan FX, et al. A randomized multicenter study of remifentanil compared with halothane in neonates and infants undergoing pyloromyotomy. 1. Emergence and recovery profiles. Anesth Analg 2001; 93: 1380-6.

14 Campbell BT, McLean K, Barnhart DC, Drongowski, Hirschl RB. A comparison of laparoscopic and open pyloromyotomy at a teaching hospital. J Pediatr Surg 2002; 37: 1068-71.

15 Caceres $M$, Liu D. Laparoscopic pyloromyotomy : redefining the advantages of a novel technique. JSLS 2003; 7: 123-7.

16 Chipps BE, Moynihan R, Schieble T, et al. Infants undergoing pyloromyotomy are not at risk for postoperative apnea. Pediatr Pulmonol 1999; 27: 278-81.

17 Andropoulos DB, Heard MB, Johnson KL, Clarke JT, 
Rowe $R W$. Postanesthetic apnea in full-term infants after pyloromyotomy. Anesthesiology 1994; 80: 216-9.

18 Habre W, Schwab C, Gollow I, Johnson C. An audit of postoperative analgesia after pyloromyotomy. Paediatr Anaesth 1999; 9: 253-6.

19 Garza JJ, Morash D, Dzakovic A, Mondschein JK, Jaksic $T$. Ad libitum feeding decreases hospital stay for neonates after pyloromyotomy. J Pediatr Surg 2002; 37: 493-5.

20 White JS, Clements WDB, Heggarty P, et al. Treatment of infantile hypertrophic pyloric stenosis in a district general hospital: a review of 160 cases. J Pediatr Surg 2003; 38: 1333-6.

21 Dubé S, Dubé P, Hardy JF, Rosenfeld RE.

Pyloromyotomy of Ramstedt: experience of a nonspecialized centre. Can J Surg 1990; 33: 95-6.

22 Saunders MP, Williams CR. Infantile hypertrophic pyloric stenosis: experience in a district general hospital. J R Coll Surg Edinb 1990; 35: 36-8.

23 Pranikoff T, Campbell BT, Travis J, Hirschl RB. Differences in outcome with subspecialty care: pyloromyotomy in North Carolina. J Pediatr Surg 2002; 37: 352-6.

24 Tiret L, Nicoche $\Upsilon$, Hatton F, et al. Complications related to anesthesia in infants and children. A prospective study of 40,240 anesthetics. Br J Anaesth 1988; 61: 263-9.

25 Cohen MM, Cameon CB, Duncan PG. Pediatric anesthesia morbidity and mortality in the perioperative period. Anesth Analg 1990; 70: 160-7.

26 Keenan RL, Shapiro JH, Dawson K. Frequency of anesthetic cardiac arrests in infants: Effects of pediatric anesthesiologists. J Clin Anesth 1991; 34: 433-7.

27 Elia JC. Lingual tonsillitis. Ann N Y Acad Sci 1959; 82: 52-6.

28 Jones DH, Coble SD. Unanticipated difficult airway secondary to lingual tonsillar hyperplasia. Anesth Analg 1993; 77: 1285-8.

29 Guarisco JL, Littlewood SC, Butcher RB III. Severe upper airway obstruction in children secondary to lingual tonsil hypertrophy. Ann Otol Rhinol Laryngol 1990; 99: 621-4.

30 Conacher ID, Meikle D, O'Brien C. Tracheostomy, lingular tonsillectomy and sleep-related breathing disorders. Br J Anaesth 2002; 88: 724-6.

31 Nakazawa K, Ikeda D, Ishikawa S, Makita K. A case of difficult airway due to lingual tonsillar hypertrophy in a patient with Down's Syndrome. Anesth Analg 2003; 97: 704-5.

32 Tokumine J, Sugahara K, Ura M, Takara I, Oshiro M, Owa T. Lingual tonsil hypertrophy with difficult airway and uncontrollable bleeding. Anaesthesia 2003; 58: 385-402.
33 Mamede RC, De Mello-Filho FB, Vigario LC, Dantas $R O$. Effect of gastroesophageal reflux on hypertrophy of the base of the tongue. Otolaryngol 1988; 449: 123-5.

34 Parbam K, Newman R. Recurrent lingual tonsil hyperplasia. Arch Otolaryngol Head Neck Surg 2003; 129: 1010-2.

35 Fundingsland BW, Benumof JL. Difficulty using a laryngeal mask airway in a patient with lingual tonsil hyperplasia. Anesthesiology 1996; 84: 1265-6.

36 Fitzpatrick PC, Guarisco JL. Pediatric airway foreign bodies. J La State Med Soc 1998; 150: 138-41.

37 Lifschultz BD, Donoghue ER. Deaths due to foreign body aspiration in children: the continuing hazard of toy balloons. J Forensic Sci 1996; 41: 247-51.

38 Babarloo F, Veyckemans F, Francis C, Biettlot M-P, Rodenstein DO. Tracheobronchial foreign bodies: presentation and management in children and adults. Chest 1999; 115: 1357-62.

39 Karakoç F, Karadag B, Akbenlioglu C, et al. Foreign body aspiration: what is the outcome? Pediatr Pulmonol 2002; 34: 30-6.

40 Bugmann P, Birraux J, Barrazzone C, Fior A, Le Coultre C. Severe bronchial synechia after removal of a long-standing bronchial foreign body; a case report to support control bronchoscopy. J Pediatr Surg 2003; 38: E14-6.

41 Swanson KL, Prakash UBS, Midthun DE, et al. Flexible bronchoscopic management of airway foreign bodies in children. Chest 2002; 121: 1695-700.

42 Yazbeck-Karam VG, Aouad MT, Baraka AS. Laryngeal mask airway for ventilation during diagnostic and interventional fiberoptic bronchoscopy in children. Paediatr Anesth 2003; 13: 691-4.

43 Brown L, Sherwin T, Perez JE, Perez DU. Heliox as a temporizing measure for pediatric foreign body aspiration. Acad Emerg Med 2002; 9: 346-7.

44 Fraga JC, Neto AM, Seitz E, Schopt L. Bronchoscopy and tracheotomy removal of bronchial foreign body. J Pediatr Surg 2002; 37: 1239-40.

45 Brown KL, Shefler A, Cohen G, et al. Near-fatal grape aspiration with complicating acute lung injury successfully treated with extracorporeal membrane oxygenation. Pediatr Crit Care Med 2003; 4: 243-5.

46 Lang SA, Duncan PG, Shepard DA, Ha HC. Pulmonary oedema associated with airway obstruction. Can J Anaesth 1990; 37: 210-8. 